\title{
Avaliação do potencial antioxidante frente à oxidação lipídica e da toxicidade preliminar do extrato e frações obtidas das frondes de Dicksonia sellowiana (Presl.) Hook.
}

OLIVEIRA, V.B. ${ }^{*} ;$ ZUCHETTO, M.'; PAULA, C.S.1; VERDAM, M.C.S. ${ }^{1}$ CAMPOS, R.'; DUARTE, A.F.S.1; MIGUEL, M.D.'; MIGUEL, O.G.'1

'Universidade Federal do Paraná, Departamento de Farmácia, Programa de Pós Graduação em Ciências Farmacêuticas. Av. Pref. Lothário Meissner, 632 -. Jardim Botânico, CEP 80210-170, Curitiba, PR, Brasil. *Autor para correspondência: vinicius.bednarczuk@hotmail.com

\begin{abstract}
RESUMO: A espécie Dicksonia sellowiana, conhecida popularmente como xaxim, é uma samambaia natural do continente americano e encontrada no Brasil na Mata Atlântica. Em 2001 foi inserida na lista do IBAMA como espécie ameaçada de extinção em decorrência da exploração para a confecção de vasos para a jardinagem. $O$ presente trabalho descreve 0 potencial antioxidante lipídico (TBARS e Sistema $\beta$-caroteno/ácido linoleico) do extrato bruto e frações obtidos através de aparato de Soxhlet de frondes de Dicksonia sellowiana, além da atividade citotóxica e hemolítica in vitro. Pelo método TBARS, todas as amostras testadas apresentaram atividade, destacando a fração acetato de etila e extrato bruto cuja atividade foi comparável ao padrão ácido ascórbico. No sistema $\beta$-caroteno/ácido linoleico, a fração acetato de etila e extrato bruto apresentaram inibição da oxidação do ácido linoleico, destaque para a fração acetato de etila que não se diferenciou estatisticamente do padrão BHT. Na avaliação da toxicidade preliminar, não fora observado atividade citotóxica e hemolítica do extrato bruto e frações nos modelos testados. Os resultados demonstram o potencial antioxidante da espécie vegetal nos modelos de inibição da oxidação lipídica sem apresentar toxicidade.
\end{abstract}

Palavras-chave: Antioxidante, peroxidação lipídica, hemolítica, Artemia salina, Dicksoniaceae.

\begin{abstract}
Evaluation of antioxidant potential against lipid oxidation and preliminary toxicity of extract and fractions obtained from the fronds of Dicksonia sellowiana (Presl.) Hook. The species Dicksonia sellowiana, popularly known as tree fern, are a natural fern from American continent found in the Atlantic Forest in Brazil. In 2001 it was added to the list of IBAMA as endangered species due to its exploitation for pots craft for gardening species. This paper describes the antioxidant lipid potential (TBARS and System $\beta$-carotene / linoleic acid) of the crude extract and fractions obtained by Soxhlet apparatus of Dicksonia sellowianafronds, besides the cytotoxic and hemolytic activity in vitro. By the TBARS method, all samples tested showed activity, particularly the fraction ethyl acetate and the crude extract whose activity was comparable to standard ascorbic acid. In the system $\beta$-carotene / linoleic acid, the fraction of ethyl acetate and crude extract inhibited the oxidation of linoleic acid, especially the ethyl acetate fraction which did not differ statistically from the standard BHT. In a preliminary assessment of toxicity,cytotoxic and hemolytic activity of crude extracts and fractions in the tested models were not observed. The results of this study indicate the antioxidant potential of this plant species in models of inhibiting lipid oxidation without producing toxicity.
\end{abstract}

Keywords: Antioxidant, lipid peroxidation, hemolytic, Artemia salina, Dicksoniaceae.

\section{INTRODUÇÃO}

Diversas funções fisiológicas são controladas por vias que envolvem reações de troca de elétrons por redução e oxidação, como a produção aumentada de espécies reativas a oxigênio (EROS) por leucócitos em processos inflamatórios e também em processos que envolvem adesão celular, como embriogênese, diferenciação, reparo e cicatrização (Silva \& Jasiulionis, 2014). 
Doenças neurodegenerativas, problemas cardiovasculares e o processo de envelhecimento têm sido relacionadas com os altos níveis de radicais livres, que são gerados intrinsicamente pelo próprio metabolismo por meio do processo de combustão do oxigênio e também através de fatores extrínsecos como cigarro, álcool, poluição ambiental entre outros (Valko et al. 2007 ).

Os seres vivos possuem mecanismos de defesa antioxidante próprios, que, com avançar da idade, se tornam insuficientes (Hirata et al. 2004 ). Neste sentido, as plantas que combatem o estresse oxidativo causado pelos radicais livres e outras espécies reativas a oxigênio, vislumbram como uma possibilidade no desenvolvimento de novos medicamentos destinados ao tratamento de doenças relacionadas aos radicais livres (Nariya et al., 2012).

No aspecto prático, a procura por novas substâncias com potencial antioxidante, principalmente de origem natural, tem sido objeto de diversos estudos contribuído com o interesse científico (Oliveira et al. 2009 ). Desta forma, os compostos fenólicos, devido as suas hidroxilas estão correlacionados com aumento do potencial antioxidante no plasma e são reconhecidos pela proteção vascular (Mertens-Talcott et al. 2008 ).

A família Dicksoniaceae é uma pequena família de filicíneas arborescentes. As espécies desta família são fetos tropicais, subtropicais e de latitudes temperadas quentes, encontradas em regiões tropicais do hemisfério sul, atingindo áreas temperadas como o sul da Nova Zelândia (Joly, 1985). A maioria dos gêneros da família se caracteriza por serem rasteiros e possuírem troncos muito pequenos, porém, algumas das maiores espécies podem atingir vários metros de altura (Mielke, 2002).

Representante desta família, a espécie vegetal Dicksonia sellowiana (Presl.) Hook., conhecida popularmente como xaxim, samambaiaçu, samambaiaçu-imperial e feto arborescente, é natural do continente americano, possuindo registros desde o sul do México até o Uruguai, passando pela América Central, Venezuela, Colômbia, Bolívia, Paraguai e Brasil (Tryon \& Tryon, 1982).

Espécie característica da floresta ombrófila mista na mata Atlântica, o xaxim até 2001 era muito utilizado na confecção de vasos para jardinagem, motivo que levou esta espécie para a lista oficial do IBAMA (Instituto Brasileiro do Meio Ambiente e dos Recursos Naturais Renováveis) de espécies brasileiras ameaçadas de extinção (Brasil, 2008). Pouco estudada cientificamente sobre seus aspectos químicos e biológicos, recentemente estudos demonstraram que o extrato bruto possui ação nos receptores muscarínicos na atividade vasorrelaxante e hipotensora em camundongos (Rattmann et al. 2009), popularmente tem sido utilizada por diferentes vias (oral, tópico ou de inalação) para tratar asma, pele, doenças cardiovasculares e doenças parasitárias (Corrêa, 1984; Marquesini, 1995).

Diversas técnicas têm sido utilizadas para determinar a atividade antioxidante in vitro, permitindo uma rápida seleção de substâncias e/ou misturas com potencial interessantes na prevenção de doenças crônico-degenerativas. Dentre estes métodos, destacam-se o sistema de co-oxidação do $\beta$-caroteno/ácido linoleico (Alves et al. 2010), e o método de quantificação de TBARS muito utilizado para estimar peroxidação lipídica nas membranas e sistemas biológicos (Rael et al. 2004).

Tendo isto, o objetivo deste trabalho foi avaliar o extrato etanólico e frações das frondes de Dicksonia sellowiana Hook, com relação ao potencial antioxidante in vitro por métodos oxidativos além da atividade citotóxica frente Artemia salina e atividade hemolítica.

\section{MATERIAL E MÉTODOS Material Vegetal}

Por tratar-se de uma espécie ameaçada de extinção, este estudo possui autorização do IBAMA para acesso ao patrimônio genético por meio da Autorização n. ${ }^{\circ} 023 / 2010$, para fins de pesquisa científica, atendendo os requisitos descritos na resolução $n^{\circ} 35$, de 27 de abril de 2011 que dispõe sobre a regularização de atividade de acesso ao patrimônio genético. As frondes de Dicksonia sellowiana (Presl.) Hook, da espécie adulta em fase vegetativa, foram coletadas na chácara da empresa CHAMEL $®$ localizada na cidade de Inácio Martins, Paraná, com localização via GPS S $25^{\circ} 29^{\prime} 35,7^{\prime \prime}$ WO $51^{\circ} 12^{\prime}$ 00.0", em abril de 2010. A identificação e depósito da exsicata foi realizada no Museu Botânico de Curitiba sob o número 358323 . Todo o material vegetal utilizado trata-se de material de cultivo da empresa CHAMEL, que possui em sua chácara aproximadamente 2.000 exemplares da espécie.

\section{Preparo dos extratos vegetais}

As frondes foram secas em estufa com circulação de ar forçada na temperatura de $50{ }^{\circ} \mathrm{C}$ por um período aproximado de 36 horas e trituradas em moinho de facas/martelo. O extrato bruto etanólico foi obtido a partir de $2 \mathrm{Kg}$ de frondes secas e trituradas através de extração exaustiva por meio de aparelho de Soxhlet utilizando como solvente 7 litros de álcool de cereais. Na sequência, o extrato foi filtrado em funil de Büchner e concentrado em rota-evaporador e, após este processo, foi mantido em banho-maria $\left(60^{\circ} \mathrm{C}\right)$ até chegar ao volume de 
$200 \mathrm{~mL}$. Deste volume, separou-se $20 \mathrm{~mL}$ que foi levado à secura. $O$ restante (aproximadamente $180 \mathrm{~mL}$ ) foi utilizado para obtenção das frações por partição líquido/líquido utilizando aparato de Soxhlet modificado com solventes de polaridade crescente (n-hexano, clorofórmio e acetato de etila) (Carvalho et al. 2009). Cada fração foi submetida a rota-evaporador para remoção do solvente e posteriormente mantida em banho-maria $\left(60^{\circ} \mathrm{C}\right)$ até eliminação total do solvente. A partir do extrato bruto (EB), frações hexano (FH), clorofórmio $(F C)$, acetato de etila (FAE) e hidroalcoólica residual (FR) das frondes foram realizados os ensaios propostos.

\section{Ensaio Antioxidante pelo Método do Ácido Tiobarbitúrico- Espécies Reativas (TBARS)}

A atividade dos extratos e frações sob a formação do malonaldeído (MDA) a partir da oxidação de ácidos graxos insaturados foi analisado espectrofotometricamente segundo metodologia modificada por Morais et al. (2006). Em tubos de ensaio, foram adicionados $0,5 \mathrm{~mL}$ de solução de gema de ovo $(10 \% \mathrm{p} / \mathrm{v}), 0,1 \mathrm{~mL}$ de amostra ou padrão (100, 500 e 1000 ppm) e completado o volume para $1 \mathrm{~mL}$ com água destilada. Após este processo, acrescentou-se a cada um dos tubos de ensaio, 0,05 mL de solução de 2,2'-azobis(2amidinopropano) dihidrocloreto (ABAP) 0,07 mol.L-1, $1,5 \mathrm{~mL}$ de solução de ácido acético $20 \%(\mathrm{pH} 3,5)$ e 1,5 mL de solução de ácido tiobarbitúrico (TBA) $0,8 \% \mathrm{p} / \mathrm{v}$ em solução de dodecil sulfato de sódio $1,1 \% \mathrm{p} / \mathrm{v}$. Os tubos foram fechados e mantidos em banho-maria à $95^{\circ} \mathrm{C}$ por $60 \mathrm{~min}$, sob agitação. Após resfriamento, foi acrescentado a cada tubo $5 \mathrm{~mL}$ de $\mathrm{n}$-butanol e centrifugados por $10 \mathrm{~min}$, a $3000 \mathrm{rpm}$. Os sobrenadantes foram submetidos ao espectrofotômetro, em $532 \mathrm{~nm}$. O mesmo processo foi realizado com 3 tubos de ensaio que não continham amostras, apenas os reagentes. Foram avaliadas as frações, o extrato bruto, e os padrões BHT (butil hidroxi tolueno) e ácido ascórbico nas mesmas proporções. Todas as amostras testadas foram realizadas em triplicata.

Aatividade antioxidante foi determinada pelo Índice Antioxidante (IA), obtido em porcentagem, segundo a Equação: IA (\%) = 1 - (Abs amostra/Abs controle) x 100, sendo, Abs amostra a absorbância da amostra e Abs controle a absorbância do controle totalmente oxidado. Os dados foram submetidos à análise de variância (ANOVA). Para comparações entre as médias dos índices de atividade (IA\%), utilizou-se o teste de Tukey. As diferenças foram consideradas estatisticamente significantes quando $\mathrm{P}<0,05$.

\section{Inibição da oxidação pelo sistema $\beta$-caroteno/ácido linoleico \\ Para determinação da atividade antioxidante} do extrato e frações utilizando o sistema $\beta$-caroteno/ ácido linoléico foi utilizada a metodologia descrita por (Miller, 1971). Para o preparo da mistura reativa $2 \mathrm{mg}$ de $\beta$-caroteno foram dissolvidos em $1 \mathrm{~mL}$ de clorofórmio, sendo transferidos $25 \mu \mathrm{L}$ para um balão volumétrico de $25 \mathrm{~mL}$, juntamente com $20 \mu \mathrm{L}$ de ácido linoleico, $200 \mathrm{mg}$ de Tween 40 e $500 \mu \mathrm{L}$ de clorofórmio. Posteriormente, a mistura foi submetida a fluxo de nitrogênio para completa evaporação do solvente. A esta mistura isenta de clorofórmio, adicionou-se aproximadamente $25 \mathrm{~mL}$ de água destilada aerada e agitou-se vigorosamente.

A mistura reativa apresentou-se límpida com absorbância em 0,6 em $470 \mathrm{~nm}$. Para determinação das absorbâncias $250 \mu \mathrm{L}$ da mistura reativa foram adicionados a $10 \mu \mathrm{L}$ do extrato bruto e frações em diferentes concentrações (100 e 200 $\mu \mathrm{g} . \mathrm{mL}^{-1}$ ) em placas de poliestireno de 96 poços. A absorbância no tempo zero foi medida em $470 \mathrm{~nm}$ usando um leitor de placa (Tecan Infinite M 200). $O$ equipamento ficou em temperatura constante de $50^{\circ} \mathrm{C}$ por um período de 2 horas, após este período foi realizada a última leitura. Um branco, sem a mistura reativa, foi preparado para posterior subtração, já que os extratos possuem coloração. Foi utilizado como padrões para este modelo o ácido ascórbico e a rutina. Todas as amostras testadas além dos padrões utilizados foram realizados em triplicata.

A atividade antioxidante (AA) foi expressa como porcentagem de inibição da oxidação usando: AA = [(absorbância após $2 \mathrm{~h}$ de ensaio/absorbância inicial) x 100]. Absorbâncias menores que 0,3 após 120 min de reação foram consideradas como 100\% de oxidação.

\section{Ensaio de toxicidade frente aos náuplios de Artemia salina}

Para o ensaio de toxicidade frente à Artemia salina foi utilizada metodologia de Meyer et al. (1982) adaptada. Preparou-se uma solução de sal marinho (35 g.L-1) para incubação dos cistos de A. salina mantidos sob aeração e agitação constantes, em uma temperatura entre 26 a $30^{\circ} \mathrm{C}$ por 48 horas para a eclosão dos mesmos, mantendo o pH entre 8 e 9 , sob iluminação constante. Após a eclosão dos cistos, 10 larvas de $A$. salina foram transferidas para tubos de ensaio contendo três concentrações $(10,100$ e $1000 \mu \mathrm{g} \cdot \mathrm{mL}^{-1}$ ) do extrato bruto, frações e controles em triplicata. Foi utilizado como controle positivo o sulfato de quinidina nas mesmas concentrações e a água do mar artificial como controle negativo. Os náuplios foram incubados por 24 horas e após este período de contato os que apresentavam

Rev. Bras. PI. Med., Campinas, v.17, n.4, p.614-621, 2015. 
mobilidade foram contados. Os dados foram analisados pelo método Probits e expressos como $\mathrm{CL}_{50}$ (concentração letal média). Foram consideradas tóxicas amostras que apresentaram $\mathrm{CL}_{50}$ menores que $1000 \mu \mathrm{g} \cdot \mathrm{mL}^{-1}$.

\section{Atividade hemolítica}

Os extratos bruto e frações das frondes foram submetidos a dois ensaios de atividades hemolíticas. No primeiro ensaio foram utilizadas placas de ágar-sangue (Newprov ${ }^{\circledR}$ ). As amostras foram preparadas a $1.000 \mu \mathrm{g} \cdot \mathrm{mL}^{-1} \mathrm{e}$ impregnadas em discos estéreis no. $1 \mathrm{com} 7 \mathrm{~mm}$ de diâmetro (Whatmann ${ }^{\circledR}$ ). Discos impregnados com o solvente foram utilizados como controle negativo, e o Triton $\mathrm{X}-100$ a $1.000 \mu \mathrm{g} \cdot \mathrm{mL}^{-1}$ como controle positivo. Depois da evaporação dos solventes, os discos foram distribuídos nas placas, que foram incubadas a 36 ${ }^{\circ} \mathrm{C}$ por 24 horas. Após este período verificou-se a formação de halo de hemólise. Os halos foram então medidos e os resultados expressos como média dos halos encontrados em triplicata utilizando como controle positivo o padrão ácido gálico a 1.000 $\mu \mathrm{g} \cdot \mathrm{mL}^{-1}$ (Kalegari et al. 2011).

O segundo método seguiu metodologia descrita na Farmacopéia Brasileira (Brasil, 2010) com adaptações. Para este método preparou-se, com sangue de carneiro desfibrinado (Newprov ${ }^{\circledR}$ ), uma suspensão a $2 \%$ em tampão fosfato $\mathrm{pH} 7,4$. As amostras (extratos e frações) $1000 \mu \mathrm{g} \cdot \mathrm{mL}^{-1}$ foram diluídas em etanol a $10 \% \mathrm{com} \mathrm{NaCl}$ a $0,9 \%$ e testado em concentrações de 1000, 500, 200 e $100 \mu \mathrm{g} . \mathrm{mL}-1$. Um volume de $1,0 \mathrm{~mL}$ da suspensão de sangue foi adicionado a 3 tubos de ensaio contendo as amostras que foram lentamente homogeneizadas, seguido de repouso por $30 \mathrm{~min}$. Decorrido este tempo, foram homogeneizadas novamente e mantidas em repouso durante mais $150 \mathrm{~min}$. Subsequentemente, as amostras foram centrifugadas durante $5 \mathrm{~min}$ a $3.000 \mathrm{rpm}$. A água destilada foi utilizada como controle positivo e tampão fosfato como controle negativo. O resultado foi descrito como presença ou ausência de hemólise baseado na tonalidade do sobrenadante após centrifugação. A presença de um precipitado de glóbulos vermelhos indicou resultado negativo. Todas as amostras e concentrações testadas foram realizadas em triplicata.

\section{RESULTADOS E DISCUSSÃO}

As EROS podem atuar em qualquer componente celular, entretanto as membranas são os componentes mais atingidos, acarretando em alterações na sua estrutura e permeabilidade, podendo levar devido à perda de seletividade e liberação do conteúdo de organelas, a formação de produtos citotóxicos como o malonaldeído, resultando na morte celular (Oliveira et al. 2009). Um órgão altamente sensível a danos oxidativos por ser rico em material lipídico é o cérebro por consumir uma quantidade significativa de oxigênio, ser relativamente deficiente em defesas antioxidantes, rico em substratos oxidáveis como ácidos graxos poli-insaturados e catecolaminas (Chong et al. 2005).

Na determinação da atividade antioxidante pelo método do TBARS (Tabela 1) observa-se que a fração acetato de etila (FAE) obtida das frondes de $D$. sellowiana obteve um índice antioxidante

TABELA 1. Redução da peroxidação lipídica promovida pelo extrato bruto e frações obtidos das frondes de Dicksonia sellowiana.

\begin{tabular}{|c|c|c|c|}
\hline \multirow[b]{2}{*}{ AMOSTRA } & \multicolumn{3}{|c|}{ CONCENTRAÇÃO (ppm) } \\
\hline & 1000 & 500 & 100 \\
\hline & $\mathrm{IA}(\%)$ & $\mathrm{IA}(\%)$ & $\mathrm{IA}(\%)$ \\
\hline $\mathrm{BHT}$ & $90,75 \pm 1,475$ & $80,66 \pm 0,729 p$ & $67,4 \pm 1,173 \mathrm{mn}$ \\
\hline VIT. C & $72,38 \pm 0,743 \circ$ & $59,77 \pm 1,08 \mathrm{jk}$ & $45,36 \pm 1,988 \mathrm{fg}$ \\
\hline EB & $67,88 \pm 0,365 \mathrm{mn}$ & $60,34 \pm 1,114 \mathrm{jk}$ & $51,09 \pm 1,931 \mathrm{~h}$ \\
\hline $\mathrm{FH}$ & $29,07 \pm 1,603$ & $20,85 \pm 2,252 b$ & $5,94 \pm 1,826$ \\
\hline FC & $44,9 \pm 2,158$ & $35,92 \pm 0,697 \mathrm{de}$ & $29,83 \pm 0,95$ \\
\hline FAE & $70,48 \pm 0,898$ по & $57,98 \pm 1,091 j$ & $44,88 \pm 1,352$ \\
\hline FR & $51,31 \pm 1,091 \mathrm{~h}$ & $34,17 \pm 1,148$ & $22,5 \pm 1,071$ \\
\hline
\end{tabular}

EB - Extrato Bruto, FH - Fração Hexânica, FC - Fração Clorofórmio, FAE - Fração Acetato de Etila, FR - Fração Hidroalcoólica Residual, VIT C - Vitamina C. IA\% \pm = Índice Antioxidante \pm Desvio padrão seguidos das mesmas letras não diferem entre si ao nível de $5 \%$ pelo teste de Tukey.

Rev. Bras. PI. Med., Campinas, v.17, n.4, p.614-621, 2015. 
(IA) de 70,48\% na concentração de 1000 ppm, não diferenciando estatisticamente do padrão ácido ascórbico $(72,38 \%)$ na mesma concentração, enquanto a fração hexano $(29,07 \%)$ foi a que obteve o o menor resultado por este método na mesma concentração testada. Ressalta-se também a atividade antioxidante do EB nas três concentrações testadas, apresentando na concentração de 1000 ppm um resultado de $67,88 \%$, e nas outras duas concentrações testadas os resultados foram superiores ao padrão vitamina $\mathrm{C}$ conforme pode ser visualizado na tabela 01.

Além do alto desempenho antioxidante da FAE contra a peroxidação lipídica, neste ensaio o EB e frações foram capazes de inibir a formação do MDA dos ácidos graxos reduzindo a peroxidação lipídica eficientemente. Observa-se que, com o aumento das concentrações em todas as amostras testadas, houve aumento na inibição da peroxidação lipídica, enfatizando o EB e FAE na concentração de 500 ppm com resultado superior a 50\% na inibição da peroxidação lipidica.

O método baseia-se no MDA formado a partir da oxidação de ácidos graxos insaturados com menos de três duplas ligações como o ácido linoleico, através da oxidação secundária de compostos carbonílicos (Guimarães et al. 2010). Esta reação é visualizada pela formação de um cromóforo rosado através da reação do TBA com o MDA (Dawn-Linsley et al. 2005).

A capacidade da FAE e do EB em inibir a formação do MDA é muito próxima ao padrão ácido ascórbico, mostrando que estas duas amostras agem na redução da peroxidação lipídica atuando como antioxidantes. O ácido ascórbico é um padrão muito utilizado em modelos antioxidante por possuir diversas funções fisiológicas, entre elas o alto poder antioxidante reciclando a vitamina $\mathrm{E}$ no processo de peroxidação lipídica das membranas e lipoproteínas (Vasconcelos et al. 2007). Nos alimentos industrializados, os compostos mais utilizados para inibir a oxidação lipídica são o butilhidroxi-anisol (BHA), butil-hidroxi-tolueno (BHT), terc-butil-hidroxi-quinona (TBHQ), tri-hidroxi-butilfenona (THBP) e galato de propila (GP), porém alguns estudos tem demonstrado que estes antioxidantes podem apresentar alguns efeitos tóxicos (Haslam, 1996).

Os estudos químicos e biológicos envolvendo samambaias gigantes na literatura é bastate escasso. Contudo, um estudo realizado por Rattmann et al. (2011) demonstra que o extrato bruto de $D$. sellowiana apresenta excelentes resultados no método do sequestro do radical DPPH e atividade antioxidante em células endoteliais de ratos.

No presente estudo, outro ensaio utilizado foi o sistema $\beta$-caroteno/ácido linoleico. Este método tem sido muito utilizado para avaliar a atividade antioxidante de extratos vegetais em modelos de atividade antioxidante com o objetivo de avaliar o grau de inibição da oxidação (Alves et al. 2010). Foram testadas o EB e frações de $D$. selowiana, avaliando a atividade de inibição de radicais livres gerados durante a peroxidação do ácido linoleico (Duarte-Almeida et al. 2006), e cujo os resultados estão apresentados na tabela 2.

De acordo com os resultados da avaliação da capacidade do extrato e frações na inibição da ação oxidante do ácido linoleico, observa-se que a FAE seguida do EB obtiveram resultados superiores ao padrão rutina na concentração de $200 \mu \mathrm{g}$, com ênfase na FAE não diferenciando estatisticamente do padrão BHT na mesma concentração testada. Com relação a FC e FR, ambas também apresentaram

TABELA 2. Atividade antioxidante determinada pelo Sistema $\beta$-caroteno/ácido linoleico do extrato e frações obtidas das frondes de Dicksonia sellowiana.

\begin{tabular}{|c|c|c|}
\hline \multirow{3}{*}{ Amostras } & \multicolumn{2}{|c|}{ Concentrações } \\
\hline & $100 \mu \mathrm{g}$ & $200 \mu \mathrm{g}$ \\
\hline & $\mathrm{AA}(\%)$ & $\mathrm{AA}(\%)$ \\
\hline $\mathrm{FH}$ & & \\
\hline $\mathrm{FC}$ & $53,45 \pm 0,574$ & $69,64 \pm 0,511 b c$ \\
\hline FAE & $21,97 \pm 1,853$ & $92,87 \pm 1,072$ \\
\hline EB & $58,07 \pm 3,152$ & $75,31 \pm 1,398$ \\
\hline $\mathrm{FR}$ & $34,85 \pm 1,840$ & $53,62 \pm 2,305$ \\
\hline RUT & $41,39 \pm 1,144$ & $66,67 \pm 0,637$ 。 \\
\hline $\mathrm{BHT}$ & $44,06 \pm 1,048 \mathrm{e}$ & $91,39 \pm 1,777$ \\
\hline
\end{tabular}

Notas: EB - Extrato Bruto, FH - Fração Hexânica, FC - Fração Clorofórmio, FAE - Fração Acetato de Etila, FR - Fração Hidroalcoólica Residual, RUT - Rutina, BHT - Butil Hidroxi Tolueno. AA\% $\pm=$ Atividade Antioxidante \pm Desvio Padrão seguidos das mesmas letras não diferem entre si ao nível de $5 \%$ pelo teste de Tukey 
resultados superiores a $50 \%$ de inibição na concentração de $200 \mu \mathrm{g}$.

Neste modelo não foram utilizados os resultados obtidos pela vitamina $\mathrm{C}$. Como já relatado por Duarte-Almeida et al. (2006), a vitamina C age como pró-oxidante neste modelo, pois após doar os dois hidrogênios redutores, fica passível de receber elétrons, devido ao radical ascorbila formado, que é um agente oxidante (Bors \& Buettner, 1997).

Neste método, apenas a fração hexano não apresentou atividade nas concentrações testadas, sendo que as outras amostras protegeram o ácido linoleico da oxidação, impedindo a descoloração da solução reagente (Santos et al. 2003).

Relacionando os resultados obtidos nos modelos antioxidantes propostos, em ambos o EB e a FAE obtiveram os melhores resultados, com ênfase na $F A E$, demonstrando uma promissora atividade na inibição da oxidação lipídica.

Tendo em vista que muitos dos princípios ativos em plantas medicinais são compostos fenólicos que atuam no sequestro de radicais livres e na inibição da oxidação (Sánchez-Moreno, 2002), estes resultados sugerem que o EB e a FAE de $D$. sellowiana podem exercer uma proteção antioxidante em biomoléculas com caráter lipofílico.

Com relação aos resultados obtidos nos ensaios de atividade hemolítica, o EB e frações testadas, revela-se que os mesmos não apresentaram atividade. No teste preconizado pela Farmacopeia Brasileira (2010), o qual utiliza suspensão de células sanguíneas de carneiro para verificar a ruptura dos eritrócitos com formação de hemólise caracterizada pela coloração vermelha, foi observado a formação de precipitado de células, demonstrando que as amostras testadas não promoveram a hemólise. Estes resultados foram confirmados pelo método de difusão em ágar, o qual não houve a formação do halo de hemólise com o uso das amostras, enquanto que o Triton X-100 (controle positivo) promoveu a formação de um halo de $2,2 \mathrm{~cm}$.

A hemólise é caracterizada por ruptura do eritrócito com liberação de hemoglobina. A hemoglobina livre no plasma é prejudicial a saúde causando sérios danos em órgãos vitais tais como fígado, rins e coração, sendo necessário dessa maneira a observação da referida atividade (Carvalho et al. 2007). Os resultados negativos obtidos nestes modelos com o extrato e frações das frondes de $D$. sellowiana confirmam a ausência de toxicidade para membrana do eritrócito nos modelos utilizados.

Os resultados de toxicidade dos extratos e frações frente aos náuplios de $A$. salina podem ser observados na tabela 3 . O controle positivo sulfato de quinidina apresentou $\mathrm{CL}_{50}$ de $50,1 \mu \mathrm{g} \cdot \mathrm{mL}^{-1}$ enquanto os resultados obtidos para o extrato e frações para a $\mathrm{CL}_{50}$ foram superiores a 1.000 $\mu \mathrm{g} \cdot \mathrm{mL}^{-1}$, demonstrando segundo a metodologia que as amostras testadas não apresentaram toxicidade para a Artemia salina. A utilização da A. Salina em estudos toxicológicos preliminares como o realizado por Paula et al. (2014), deve-se a simplicidade, rapidez e o baixo custo favorecendo a utilização em diversos estudos (Luna, 2005).

TABELA 3. $\mathrm{CL}_{50}$ provocada pelos Extratos e Frações obtidas das frondes de D.sellowiana para náuplios de A. salina

\begin{tabular}{c|c}
\hline Amostra & $\mathrm{CL}_{50}\left(\mu \mathrm{g} \cdot \mathrm{mL}^{-1}\right)$ \\
\hline $\mathrm{FH}$ & $>1000$ \\
$\mathrm{FC}$ & $>1000$ \\
$\mathrm{FAE}$ & $>1000$ \\
$\mathrm{FR}$ & $>1000$ \\
$\mathrm{~EB}$ & $>1000$ \\
\hline Sulfato de Quinidina & 50,1 \\
\hline
\end{tabular}

NOTAS: EB - Extrato bruto, FH - Fração Hexânica, FC Fração clorofórmio, FAE - Fração Acetato de etila, FR - Fração Hidroalcoólica Residual.

Ensaios de toxicidade preliminar funcionam como uma ótima ferramenta nos estudos com plantas medicinais e devem ser implementados, pois auxiliam na diminuição do uso de animais na experimentação, o que vem sendo uma preocupação dos Comitês de ética em experimentação animal (Bednarczuk et al. 2010)

Os resultados obtidos neste estudo demonstram que o extrato obtido de frondes da espécie vegetal $D$. sellowiana atua como inibidor da oxidação lipídica, podendo também servir como fonte de substâncias antioxidantes que poderão ser utilizadas em doenças como as cardiovasculares, neurodegenerativas e no combate ao envelhecimento que estão relacionadas aos modelos propostos. A ausência de toxicidade nos modelos testados estimula a realização de novas pesquisas na área química e farmacológica para determinar as propriedades terapêuticas que esta espécie possui.

\section{AGRADECIMENTOS}

A CAPES, REUNI/ CAPES e CNPQ pela concessão das bolsas de estudo e financiamento do projeto. 


\section{REFERÊNCIAS}

ALVES, C.Q. et al. Métodos para determinação de atividade antioxidante in vitro em substratos orgânicos. Química Nova, v. 33, n. 10, 2010.

BEDNARCZUK, V.O. et al. Testes in vitro e in vivo utilizados na triagem toxicológica de produtos naturais. Revista Visão Acadêmica, v. 11, n.2, p. 43, 2010.

BORS, W.; BUETTNER, G.R. The vitamin C radical and its reactions In: Packer, L. and Fuchs, J. Vitamin C in Health and Disease. New York, Marcel Dekker, Inc. cap. 4, p. 75-94, 1997.

BRASIL. ANVISA. Agência nacional de vigilância sanitária. Farmacopeia Brasileira, 5 ed. p. 546. 2010.

BRASIL. Lista oficial de espécies brasileiras ameaçadas de extinção. Brasília: Instrução normativa $M M A n^{\circ} 6$, de 23 de setembro de 2008.

BRASIL. MMA. Ministério do meio ambiente - Resolução $n^{\circ} 35$, de 27 de abril de 2011.

CARVALHO, J.L.S. et al. Termoestabilidade de processos extrativos de Nasturtium officinale R. Br., brassicaceae por sistema Soxhlet modificado. Química Nova, vol.32, n.4, p. 1031-1035, 2009.

CARVALHO et al. Efeito da bomba de infusão de soluções sobre o graus de hemólise em concentrados de hemácias. Revista Brasileira de Hematologia e Hemoterapia. v. 29, n. 2. p.149-152, 2007

CHONG, Z.Z. et al. Oxidative stress in the brain: Novel cellular targets that govern survival during neurodegenerative disease. Progress in Neurobiology, v. 75, n.3, p. 207-246. 2005.

CORREA, M.P. Dicionário de plantas úteis do Brasil e das exóticas cultivadas. v. 2 Imprensa Nacional, Brasil. p. 209-210. 1984.

DAWN-LINSLEY M. et al. Monitoring thiobarbituric acidreactive substances (TBARs) as an assay for oxidative damage in neuronal cultures and central nervous system. Journal of Neuroscience Methods. v. 141, n.2, p. 219-222, 2005.

DUARTE-ALMEIDA, J.M. et al. Avaliação da atividade antioxidante utilizando sistema beta-caroteno/ ácido linoléico e método de seqüestro de radicais $\mathrm{DPPH}$ • Ciência e Tecnologia de Alimentos, v. 26, n. 2, 2006

GUIMARÃES, A.G. et al. Bioassay-guided Evaluation of Antioxidant and Antinociceptive Activities of Carvacrol. Basic \& Clinical Pharmacology \& Toxicology, v. 107, n.6, p. 949-957, 2010.

HASLAM, E., Natural Polyphenols (Vegetable Tannins) as Drugs: Possible Modes of Action, Journal of Natural Products, v. 59, n. 2, p. 205-215, 1996.

HIRATA, L.L. et al. Radicais livres e o envelhecimento cutâneo. Acta Farmaceutica Bonaerense, v. 23, n. 3, p 418-424, 2004.

JOLY, A.B. Botânica: Introdução à taxonomia vegetal. 7. ed. São Paulo: Ed. Nacional, p.173-174. 1985.

KALEGARI, M. et al. Phytochemical constituents and preliminary toxicity evaluation of leaves from Rourea induta Planch. (Connaraceae). Brazilian Journal of Pharmaceutical Sciences, v. 47, n. 3, p. 635-642, 2011.

LUNA, J.S. et al. A study of the larvicidal and molluscicidal activities of some medicinal plants from northeast Brazil. Journal of Ethnopharmacology. v. 97, n. 2, p. 199 -
206, 2005.

MARQUESINI, N.R. Plantas usadas como medicinais pelos índios do Paraná e Santa Catarina, Sul do Brasil: Guarani, Kaingãng, Xokleng, Ava-Guarani, Kraô e Cayua. Universidade Federal do Paraná. Curitiba, Brasil. 1995.

MERTENS-TALCOTT, S.U. et al. Pharmacokinetics of anthocyanins and antioxidant effects after the consumption of anthocyanin-rich açai juice and pulp (Euterpe oleracea Mart.) in human healthy volunteers. Journal of Agricultural and Food Chemistry, v.56, p.7796-802, 2008.

MEYER, B.N. et al. Brine shrimp: a convenient general bioassay for active plant constituents. Planta Medica, v.45, n.1, p.31-34, 1982.

MIELKE, E.J.C. Análise da cadeia produtiva e comercialização do xaxim Dicksonia sellowiana, no Estado do Paraná. 2002. Dissertação (Mestrado em engenharia florestal) Universidade Federal do Paraná.

MILLER, H.E. A simplified method for the evaluation of antioxidant. Journal of the American Oil Chemists, v. 48, p. 91, 1971.

MORAIS, S.M. et al. Antioxidant activity of essential oils from Northeastern Brazilian Croton species. Química Nova, v. 29, n. 5, p. 907-910, 2006.

NARIYA, P.B., SHUKLA, V.J., ACHARYA, R.N. Phytochemical screening and in vitro evaluation of free radical scavenging activity of Cordia macleodii bark. Free Radical Antioxidant, v. 2, n.3, p 36-40, 2012.

OLIVEIRA, A.C. et al. Fontes vegetais naturais de antioxidantes. Química Nova, v. 32, n. 3, 2009

PAULA, C.S. et al . Atividade antioxidante e toxicidade preliminar do extrato e frações obtidas das folhas e cascas do caule de Dasyphyllum tomentosum (Spreng.) Cabrera.Revista Brasileira de Plantas Medicinais, v. 16, n. 2, 2014

RAEL, L.T. et al. Lipid peroxidation and the thiobarbituric acid assay: standardization of the assay when using saturated and unsaturated fatty acids. Journal of Biochemistry and Molecular Biology. v. 37, p 749-752, 2004.

RATTMANN, Y.D. et al. Activation of muscarinic receptors by a hydroalcoholic extract of Dicksonia sellowiana Presl. HooK (Dicksoniaceae) induces vascular relaxation and hypotension in rats. Vascular Pharmacology, v. 50, n. 1-2, p. 27-33, 2009.

RATTMANN, Y.D. et al. Standardized extract of Dicksonia sellowiana Presl. Hook (Dicksoniaceae) decreases oxidative damage in cultured endothelial cells and in rats. Journal of Ethnopharmacology, v. 133, n. 3, p. 999-1007, 2011.

SÁNCHEZ-MORENO, C. Review: Methods Used to Evaluate the Free Radical Scavenging Activity in Foods and Biological Systems. Food Science and Technology International. v. 8, p. 121-137, 2002.

SANTOS, L.C. et al . Atividade antioxidante de xantonas isoladas de espécies de Leiothrix (Eriocaulaceae). Revista brasileira de farmacognosia, v. 13, n. 2, 2003.

SILVA, C.T., JASIULIONIS, M.G. Relação entre estresse oxidativo, alterações epigenéticas e câncer. Ciência e Cultura, v. 66, n.1, 2014. 
TRYON, R.M.; TRYON, A F. Ferns and allied plants with special reference to Tropical America. New York: Spring - Verlag. p. 144 - 149. 1982.

VALKO, M. et al. Free radicals and antioxidants in normal physiological functions and human disease. International Journal of Biochemistry \& Cell
Biology, v. 39, n.1. 2007.

VASCONCELOS, S.M.L. et al. Espécies reativas de oxigênio e de nitrogênio, antioxidante e marcadores de dano oxidativo em sangue humano: principais métodos analíticos para sua determinação. Química Nova, v. 30, p. 1323, 2007. 